\title{
On the magnitude, frequency, and nature of marriage dissolution in Italy: insights from vital statistics and life-table analysis
}

\author{
Antonella Guarneri ${ }^{1}$, Francesca Rinesi ${ }^{1}$, Romina Fraboni ${ }^{1}$ and Alessandra De Rose ${ }^{2^{*}}$ (1)
}

\author{
*Correspondence: \\ alessandra.derose@uniroma1.it \\ ${ }^{2}$ Sapienza University of Rome, \\ Rome, Italy \\ Full list of author information \\ is available at the end of the \\ article
}

\begin{abstract}
Legal separation is a crucial step in the dissolving of marriages in Italy. Marriage and legal separation data come from administrative data sources and have been part of the civil registration and vital statistics system for a long time. These data make it possible to constantly monitor evolution of marital unions formation and dissolution over time and space. This study highlights the potential of combining administrative data at a macro level, aggregated by selected characteristics of the marriage and of the spouses. Data collection on legal separations is a complex process that brings together records from different administrative sources that have different transmission procedures. The system has rapidly evolved in recent years because of important normative changes. Pooling the two exhaustive data sources on marriages and separations we calculate duration-specific separation rates by selected spouses' and wedding characteristics and estimate survival curves for 1975 marriage cohorts onward. Although the propensity to separate is increasing across marriage cohorts, the most recent first-marriage cohorts - those celebrated since the beginning of the new millennium — show a decreasing tendency to separate after short marriage durations. The most fragile unions are those celebrated in a civil ceremony in the north of Italy and that choose the separation of property regime. Couples in which the bride is more educated than the groom show a higher risk of separating. Differences by geographical area and celebration rite tend to reduce over time. This study contributes to existing information about the propensity to separate in Italy and the role that some characteristics of weddings and spouses play. It shows the potential for integrating information from marriage and separation registers when dealing with a relatively rare phenomenon at the population level and with information not usually collected in social surveys.
\end{abstract}

Keywords: Marital dissolution, Legal separation, Administrative data, Civil registration, Vital statistics, Italy

\section{Introduction}

The radical changes in family life that occurred all over Europe since the end of the 1960s are the distinctive patterns of what has been called the Second Demographic Transition (Lesthaeghe, 1992; Van de Kaa, 1987). This process grew out of an increasing individualization of attitudes and behaviours that multiplied options relating to the forming of 
family unions and reproductive choices, such as the postponing of union formation, the increase in premarital cohabitation, the decline in marriage and fertility, the spread of new family forms, and the increase in unions dissolution (Sobotka \& Toulemon, 2008). Changes occurred first in the countries of northern Europe and only later in the rest of Europe, at different speeds and intensities. In Italy, the decline in the number of marriages began to be noticed in the second half of the 1970s; it was not accompanied by a marked increase in consensual cohabitation, which spread only at the end of the 1990s (De-Rose et al., 2008). Even marital dissolution, although on the rise after the regulating law was introduced in 1970, remained low compared to other countries in Europe for a long time (Salvini \& Vignoli, 2011).

Studies on marital dissolution trends, determinants, and consequences have received ample space in the scientific literature for many years (Amato, 2000, 2010; Lyngstat \& Jalovaara, 2010; Mortelmans, 2020; Teachman, 2002). A number of studies on Italy, or involving the country in comparative research, highlighted the role that the socioeconomic resources of the partners and of the couple itself, namely, female education and income, play in the risks of marital dissolution (Blossfeld et al., 1995; De-Rose, 1992; Härkonen \& Dronkers, 2006; Kalmijn, 2007; Salvini \& Vignoli, 2011; Vignoli et al., 2018).

The onset of the economic recession in 2008 spurred researchers to investigate the consequences of prolonged economic hardship on household well-being, including marriage stability (Lewin, 2005). The effect is counter-cyclical: a slight decline in divorce and separation in the United States was registered, namely, in states with a higher unemployment rate (Cherlin et al., 2013). An even lower effect has been observed in most European countries, especially those with the highest frequency of divorces (González-Val \& Marcén, 2017), where the consequences of the economic crisis could be severe for families, where the marriage ended (Amato, 2010; de Vaus et al., 2017). Studies of Italy confirm that the household economic situation worsens when a union ends (Mencarini, 2009) and that the number of single parent households declaring more severe financial limitations during the economic downturn is higher than for intact families (AISP, 2015, 2021). Households where parents are separated, have low education levels, or are unemployed are at a higher risk of poverty (Natali \& Saraceno, 2017). Thus, closely following the evolution of the dissolving of marital unions and the search for related factors continues to be of particular interest, including from a policy point of view.

However, studying the determining factors of separation and divorce, as well as how they affect the well-being of individuals and families, in more depth is not easy in Italy, especially from a comparative point of view and the reconstruction of the long time series of data (Castiglioni \& Urbano, 1998; Istat, 2008). This is mainly due to the complexity of the juridical normative process and its continuous revisions over time. In addition, the relative rarity of divorce and separation until recently has, for a long time, prevented detailed analyses of their differential aspects: events of interest were difficult to detect at an individual level as secondary information obtained from sample surveys of households (Blossfeld et al., 1995; De-Rose, 1992). Even the most recent sample surveys of households-such as labour force surveys, Eu-Silc surveys, and multipurpose households surveys on daily aspects of living conditions-are not designed to properly describe the marital paths, from their beginning to the breakup and after. This is the case even though these surveys provide a more consistent 
database as a result of the dissolving of unions becoming more common in Italy and offer rich information on individual characteristics of separated partners and the effects on each household member. More specific social surveys on family dynamics are designed to capture the determinants of dissolution, but sometimes information on marital histories is incomplete (De-Rose \& Di Cesare, 2003; Salvini \& Vignoli, 2011; Vignoli \& Ferro, 2009). These reflections draw attention to the important role that the adequate use of administrative sources and vital statistics can play in following the evolution of marital dissolution in Italy and its main risk factors.

The main objective of this study is to show the potential offered by data from administrative sources and vital statistics to study marital dissolution in Italy. This study will focus on legal separations rather than divorces for two reasons. First, in Italy, legal separation represents a crucial step in the marriage disruption process and a mandatory span of time before divorce. Second, the trend in separations is not strongly altered by the major changes in the law on the process of dissolving a marriage but shows a steady increase over time.

Describing data collection flows about marriages and separations in Italy makes it possible to understand the complexity of an informative system, based on administrative data, which continuously evolves to adhere to the normative changes, and to appreciate the information potential of this source from both a statistical and a demographic point of view.

Pooling data on marriages and legal separations from the two corresponding registers and following a life table approach, we calculate duration-specific separation rates and estimate survival curves by selected wedding and spouses' characteristics. This contributes to existing information on the propensity to separate across marriage cohorts in Italy and on related differential aspects.

The strength of the paper is twofold. First, we highlight the potential of combining two administrative data sources at a macro level, that is, aggregated by characteristics of the marriage and of the spouses. Second, we analyze marital disruption (and the characteristics associated with it) in a cohort perspective, by the year of marriage of the separating couples, rather than by the year in which the legal separation occurred, as is usually computed at the population level. The study also prepares the ground for future exploitation of the administrative data based on integrated micro-level information, once a unique code has been linked to the individual records of these data sources, as we discuss in the final section.

The paper is organized as follows. In the next section, we illustrate the regulatory aspects of the legal dissolution of marriages in Italy and their continuous updates and provide a brief overview of the long-time trends of marriages, separations, and divorces. In the "Studying marital dissolution" section, we propose a reflection on the data sources that can be used to study the phenomenon, especially in Italy, and on the advantages and disadvantages. The "Collecting marriage and separation data" section describes in detail the Italian civil registration and vital statistics (CRVS) system. In the "Analysis of marriage survival rates in Italy" section, we propose an analysis of the survival to separation of the cohorts of first marriages from 1975 to 2015. Finally, the "Discussion and future perspectives" section concludes and anticipates future 


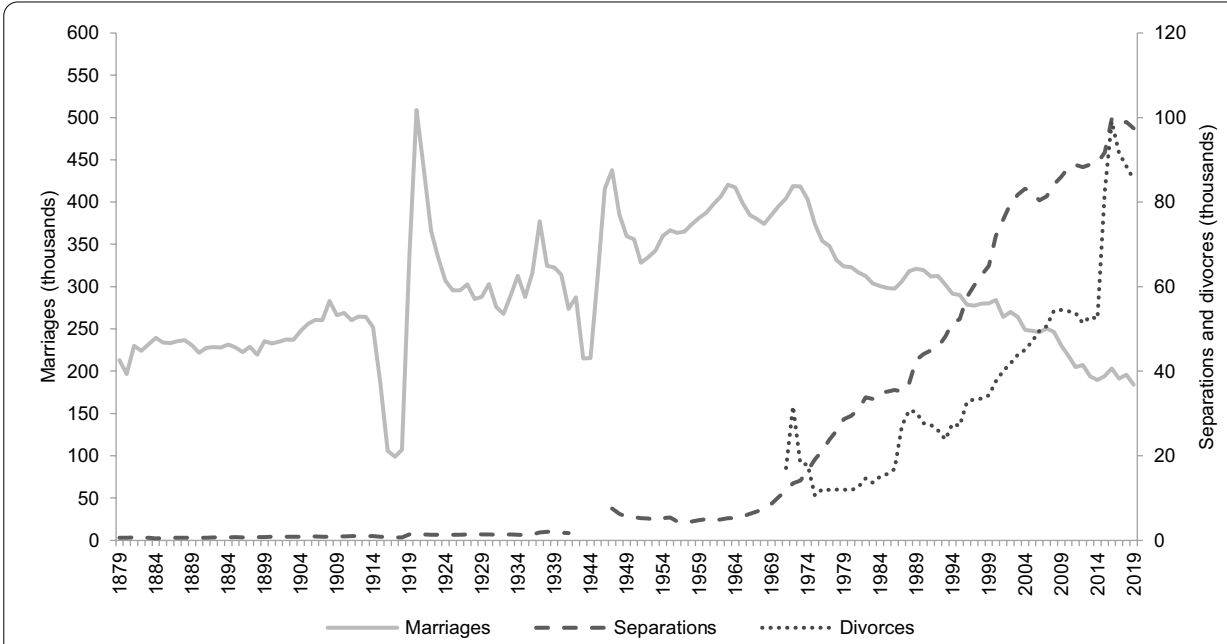

Fig. 1 Marriages (left axis) and legal separations and divorces (right axis) (in thousands), 1879-2019, Italy. Source Author's elaboration of Istat data on marriages, separations, and divorces

developments of the study, which will be made possible by the methodological and database construction advances underway in the official statistics system.

\section{The Italian context: normative aspects and main trends}

Divorce in Italy was introduced in 1970 (Law 898/1970, Discipline of Cases of Dissolution of Marriage). Access to divorce was permitted only after a legal separation of at least five years. In 1987, the first law reform reduced the compulsory length of separation before divorce to three years. Thus, separation is the first step (and often the only one), as the progression to divorce is also affected by costs and an administrative burden. Although a negligible proportion of separations lead to a reconciliation between spouses, not every legal separation ended in a divorce. For instance, of the total number of couples who legally separated in 1995, only $60 \%$ divorced in the following decade (Salvini \& Vignoli, 2011). The rest of the couples decided to stay legally separated to avoid the monetary cost and the administrative burden of a new legal formality (the divorce), which is mandatory only if one partner wishes to remarry.

The year 2014 saw another important tipping point. Two legislative changes regarding marriage disruption were introduced that further simplified the process for obtaining a divorce: Law no. 132 simplified the process of separation and divorce by mutual consent, introducing the possibility of stipulating out-of-court agreements, with a negotiation agreement assisted by lawyers (art. 6) or directly at the civil status offices. Couples could choose this option if there were no issues of paternity and underage children, or adult children who are legally incompetent, have severe disabilities, or are not economically self-sufficient (art. 12); and Law no. 55/2015 reduced the time needed between the separation and the divorce from 3 years to 6 months in cases of consensual separations or to 1 year in cases of judicial separations (Guarneri et al., 2021). 
Divorce trends are highly sensitive to legal changes: right after the approval of Law 898/1970, many couples who had been waiting divorced, but this figure sharply declined afterward and remained low until the first law reform (Fig. 1). The rigid juridical rules, which were influenced by the barriers to divorce put in place by the predominantly Catholic culture and by church institutions (Barbagli \& Saraceno, 1998), help to explain why Italy has always had one of the lowest levels of divorce in Europe. In 2007, the crude divorce rate was 0.9 dissolutions per 1,000 persons, while it was 2.2 in France and 1.5 on average in Europe overall; 10 years later, in 2017, while the average crude divorce rate in Europe reached 2.0 per 1000 persons, in Italy it was 1.5, still one of the lowest in Europe (Eurostat, 2020).

Marriage breakdown in Italy has been on the rise in the past few decades, in step with the continuous decrease in the number of marriages since the second half of the 1970s (Fig. 1). The decline in marriages is attributable both to the decrease in the propensity to marry and to the progressive reduction of the population aged 15 to 49 years due to the prolonged decline in births affecting the country. In the same period, we observed an increase in the number of legal separations and divorces both in absolute terms and relative to the number of marriages.

The latest law reform on "fast-track divorce" contributed to the recent boom in divorces, while legal separations continued to rise steadily (Istat, 2016a). From 2015 on, the number of divorces increased by $57 \%$, to 82,469 cases. The upward trend continued in 2016 (99,071 divorces), while a slowdown has been observed in the years that followed, with the most recent figure being 85,349 in 2019. The increase in legal separations in these same years (up to about 97,000 in 2019) is consistent with the long-term upward trend of marital dissolution.

Even the timing of the two processes has undergone profound changes. The mean age at marriage increased for both males and females, but the age difference between spouses is stable at around 4 years. Age at separation increased even more (from 41.6 and 38.4 for men and women, respectively, in 2000 to 48.8 and 45.5 in 2019): this can be linked to an increase in the duration of the union at separation, from 13 years on average in 2000 to 17 years in 2019 (Additional file 1: Tables S1 and S2).

\section{Studying marital dissolution: sources, pros, and cons}

Union dissolution in Italy can be studied using different sources of data that provide complementary information. These include population censuses, population-based sample surveys, and administrative data. Each data source has advantages and disadvantages and responds to different needs.

Population census data inform us about the total number of separated and divorced people at the specific date of the census, the total number of people who remarry after divorce, the characteristics of separated and divorced people, and their living conditions. These data allow comparisons to married people. However, census data do not tell us 
about any past characteristics, such as marriage date and duration, marriage characteristics (rite, place, property regime), and spouses' characteristics at marriage.

Even sample surveys tell us about the differential characteristics between married and separated people, but unlike traditional censuses, ${ }^{1}$ surveys can be more frequent. Moreover, sample surveys can provide a larger number of covariates, allowing researchers to do in-depth analyses on several aspects, such as socioeconomic and living conditions, health, and individuals' well-being. When social surveys collect information on family dynamics via retrospective questions on length of marriage and of separation, on childbearing and work histories, it is possible to study marriage duration as well as the determinants and consequences of separations on individuals and families. However, retrospective questions can be affected by recall problems and by misreporting and nonresponse; this can result in bias, namely, an overestimation of union stability (Boertien, 2020). Social sample surveys can only indirectly capture information from separated individuals about the characteristics of the former partner (such as age and education), since, by definition, he or she is no longer a member of the interviewed household. ${ }^{2}$ This is a strong limitation for the study of marriage breakdown, since the unit of analysis should be, properly, the marriage itself and not the separated partners. Longitudinal repeated surveys or panel surveys make it possible to catch changes in marital status and thus to study the determinants and consequences of separation on many different aspects, such us individuals' well-being and family organization. A drawback for studying marital dissolution is that, unlike censuses, surveys are limited by sample size, and therefore, the number of observations available for the analysis could be very low. Survey estimates are affected by sampling errors that may be quite large in the case of a rare phenomenon, as legal separations have been in Italy until recently.

Administrative data (marriages and legal separations from the civil registration system and from civil courts' information) are an important data source in Italy that is increasingly valued, as is the case in many northern European countries, for many reasons. As sample surveys are becoming more costly in the most developed countries, response rates are often decreasing, and it is necessary to limit the response burden on individuals (de Leeuw et al., 2018). Compared to sample survey data, the robustness of these exhaustive administrative data sources allows researchers to study the impact even of low-incidence characteristics on the duration of marriages. In addition, the digitization of administrative data and improved techniques for matching data from different sources are leading to broader use of administrative data for statistical purposes; the ability to extract value from data is linked to the ability to integrate data from multiple

\footnotetext{
${ }^{1}$ The census operation in Italy has undergone a profound transformation, which led to the "permanent census". Since October 2018, Istat has been conducting an annual sample survey by collecting the main characteristics of the Italian resident population and its social and economic conditions at the national, regional, and local levels. By integrating information from statistical sample surveys and data from administrative sources, the permanent census provides data annually that represents the entire population (https://www.istat.it/en/censuses/population-and-housing).

2 Occasionally, sample surveys that collect retrospective data on life events also provide information on respondents' previous partner characteristics, such as age and education level at engagement. However, it remains unknown whether the first married partner was a never-married partner, too, so it is difficult to identify first marriages of both partners. The most recent survey in Italy with indirect information on first spouse for separated people was "Family, social subjects and life-course," conducted by Istat in 2016.
} 
sources. Comparisons among sources guarantee significant gains in accuracy, coherence, and completeness of statistical data produced (Grossman et al., 2019).

The use and management of administrative data ${ }^{3}$ sources have recently increased their relevance in the production of official statistics in Italy, moving toward the exploitation of administrative data and especially giving more impulse to the process toward a register-based approach. A wide range of statistics can be produced from data held in administrative records, including statistics relating to legal or judicial separations.

There are advantages and disadvantages of using administrative data (Grossman et al., 2019; Timotfe et al., 2018; UNECE, 2007; UNECE \& World Bank Institute, 2010; UNSD, 2019). A major advantage of administrative records is their coverage: they represent a full enumeration of the relevant entities (in our case, marriages, separations, and spouses), rather than a sample. As a result, administrative data have lower costs and high accuracy, with no sampling errors and very low non-response rates. Administrative data sources gather information about events as they occur for both spouses and continuously update the corresponding records; this avoids recall errors by respondents and incurs no additional costs of collection. Besides cost savings and reduced respondent burden advantages, the comprehensiveness of administrative data is often considered one of the main advantages for research purposes, as it allows for studying low-incidence phenomena; these are usually expensive to uncover in a general population survey, as in the case of marital dissolution in Italy. Another advantage is that administrative data sources may provide data on individuals who would not normally respond to surveys because of, for instance, their moving from one area to another, language difficulties (in the case of the foreign population), social marginality, or unwillingness to provide answers in an interview. Although survey methods have progressed significantly in addressing sensitive issues, administrative data can be an accurate source of indicators for phenomena that are not easily reported by individuals, if this sensitive or confidential data can be accessed. In the case under study, there might be an underreporting of marital disruption in sample surveys when the topic is seen as intruding on the individual's privacy. Finally, administrative data typically cover long time periods and the whole territory. For these reasons, they may provide more reliable and finely disaggregated statistics compared to sample surveys. When administrative data on separations are not available, indirect measures based on other administrative data could be used to grasp information about marital disruption, such as tax data, as shown by Margolis et al. (2019). They warn about the void left by the termination of vital statistics in Canada, which can be only partially filled by this very specific data source.

However, the usefulness of administrative data may be limited by non-negligible factors. First, administrative data cover only marital dissolution, while no current information is available on informal unions that end. Second, coverage of these data reflects only entities of interest for the administrative function being performed, and the details recorded may not be current. Studying marital dissolution from an administrative data

\footnotetext{
3 According to the European Statistical System, administrative data are "data collected and maintained as a result of administrative processes, for administrative purposes, in conformity with legal bases other than statistical legislation and derived from administrative sources before any processing or validation by the statistical authorities." (European Statistics Code of Practice, as adopted by the ESSC of November 2017). See https://ec.europa.eu/eurostat/ramon/statm anuals/files/CoP_2017_Glossary.pdf.
} 
source, civil registration, can be partly affected by this drawback, as a marriage may break down without ending in a formal divorce (or a legal separation); even if such an event is registered, it may occur a certain time after the de facto breakdown and, hence, underestimate the frequency of breakdown (Murphy, 1985). Another disadvantage of the administrative data source is that it adopts definitions and classifications that may be inconsistent with those required for statistical purposes (for example, some administrative records in the labour field may cover only employees of formal businesses). This drawback is not present in the case of legal separations, as the information derives from a formal act defined by law and registered as it is. Besides, availability and timing of the marital dissolution are heavily influenced by legislative changes, which could affect data comparability over time. There is a limit to the number of covariates available in administrative data that, instead, could be easily included in sample surveys. This drawback can be overcome by integrating different data sources (see "Discussion and future perspectives"). Finally, barriers to accessing data from administrative sources could limit wider use of such data for statistical purposes. In Italy, legal acts of marriage, separation, and divorce are recorded in the civil registration system, which has a long-standing tradition of data exchange with the Italian National Institute of Statistics (Istat). These data-properly anonymized-are then made available to researchers upon request.

\section{Collecting marriage and separation data from the civil registration and vital statistics system in Italy}

In Italy, official statistics provide very long time series on all demographic phenomena related to vital statistics events, such as marriages, separations, and divorces, as shown in Fig. 1. Marriage and legal separation data are collected and published annually by Istat; they come from administrative data sources that are exhaustive, consistent with each other, and highly reliable, making it possible to monitor trends of the forming and dissolving of marriages in Italy constantly over time and space.

Both data sources contain common information about marriage characteristics (such as rite ${ }^{4}$ and property regime) that are rarely available in sample surveys and about the characteristics of both partners (such as age and education); this allows researchers to study marriage stability by joining the characteristics of both spouses.

Marriage data are taken from the marriage register and are based on information collected by the civil registrar's office in the place, where the wedding is celebrated. These are regularly transmitted to Istat via an ad hoc electronic platform using a computerassisted web interview (CAWI) technique or upload procedure. ${ }^{5}$ Marriage data cover all opposite-sex marriages registered in Italy. ${ }^{6}$

\footnotetext{
${ }^{4}$ The validity of the legal effects of Catholic marriage was recognized following the Lateran Treaty (introduced in 1929), and the distinction between religious and civil weddings started in 1930. Over time, other Christian churches and religions have signed agreements with the Italian State to regulate the civil effects of marriages celebrated by their own rites. Therefore, from a legal point of view, marriage can now be divided into three types: civil marriage celebrated by a civil registrar; Catholic marriage with civil effects celebrated by a Catholic priest; or non-Catholic marriage celebrated by ministers of the other religions admitted by the State. Statistical surveys distinguish only between religious and civil marriages, without specifying the religion.

${ }^{5}$ Web questionnaire using software developed by ISTAT (GINO + +, Gathering Information Online).

${ }^{6}$ In Italy, same-sex marriages are not allowed; however, in 2016, same-sex civil partnerships were introduced following the enactment of Law no. 76 of 20 May 2016.
} 


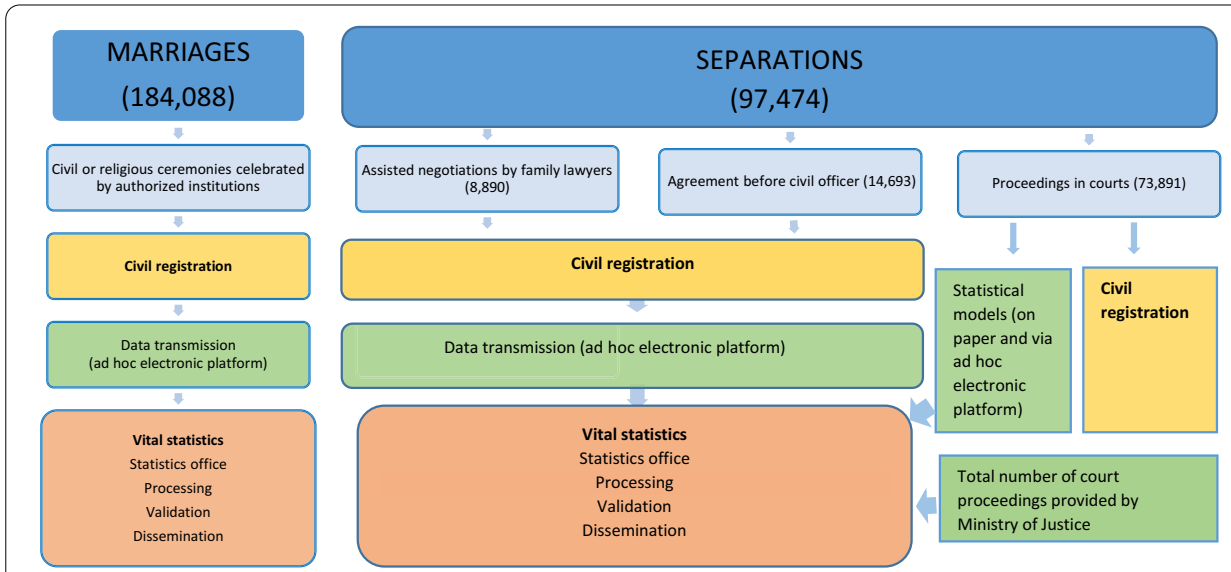

Fig. 2 Italian civil registration and vital statistics system since 2015: focus on marriages and separations (2019 data)

Until 2014, data on legal separations were collected from the courts using a questionnaire prepared by Istat. Since 2015, due to normative changes mentioned in the "Italian context" section above, data collection on legal separations has become a complex process, as it merges records from different administrative sources that follow different transmission procedures. Today, the separations register is fed by a multisource process that involves various institutions, entails different data collection flows, and requires harmonization at different stages. Harmonization concerns variables and standard classifications as well as different data characteristics and flows.

Since 2015, according to Law no. 132 art. 12, a legal separation-under certain conditions (see the "Italian context" section above) - can be agreed in front of a registrar of the civil registrar's office. This means data on legal separations include all legal separations finalized in Italy, both from the courts and from the civil registrar's office. Figure 2 presents the framework of the integrated Italian CRVS system for marriages and separations. While marriage data have a unique and well-consolidated flow from authorized institutions toward the CRVS system and then toward Istat via an electronic platform, separation (as well as divorce) data follow a more complex transmission procedure, which has been updated to reflect recent normative changes. Overall, traditional data from court proceedings cover around 75\% of separations in 2019 (almost 74,000 records), while agreements in front of the civil officer cover $15 \%$, and negotiations assisted by family lawyers cover $9 \%$. These new data flows, such as the marriage registration system, are transmitted electronically from the civil registrar's office to Istat.

For statistical purposes only, courts are asked to complete questionnaires to be sent to Istat on paper or electronically. These two data flows are then integrated to allow for monitoring of marital disruption overall. Since this process can be time consuming for court proceedings, vital statistics are fed, in the meantime, by the total number of separations (or divorces) provided by the Ministry of Justice. For this reason, it takes longer to complete data collection on separations by the courts-the majority of cases-than by civil registrar officers (which need paper questionnaires to be registered in an electronic format). This has an impact on the final dissemination of these data. 


\section{An analysis of marriage survival rates in Italy \\ Data and method}

To show the potential of the information system illustrated above, we propose a survival analysis at legal separation of marriage cohorts from 1975 to 2015. We consider legal separations that occurred yearly up to 2018 to every 5-year marriage cohort. We follow couples married in a given year grouped by given variables and count the annual losses due to legal separations classified according to the same relevant characteristics. Thus, we do not link administrative data for marriages and legal separations at the individual level, but instead combine and use the two data sources at an aggregated level of analysis and apply a cohort approach. A similar strategy was applied for Italy by Castiglioni and Dalla-Zuanna (2008), who built legal separation life tables for the marriage cohorts from 1971 to 2003, and for a recent study on divorce in Taiwan (Cheng, 2016). Unlike previous analyses on separations routinely presented by Istat (2016a) on overall marriages, here we focus on first marriages of both partners, as the share of higher order marriages is becoming significant in recent cohorts (more than 14\% in 2019); we choose to compare homogenous marriages in terms of marital experience.

Following a life table approach, we calculated duration-specific separation rates and estimated survival curves by specific characteristics. At any duration of marriage, we computed the proportion of first marriages that are still intact out of the initial size number of each cohort (Plateris, 1979; Preston \& McDonald, 1979). From the total number of first marriages at time 0 and with characteristic $k$, we subtracted the total number of related separations: that is, the legal separations out of that cohort of marriage with a given characteristics $k$ in the $t$ years following the marriage itself (Eq. 1). Then, we computed the proportion of surviving marriages at duration $t$ (per 1000), that is $\mathrm{PSM}_{\mathrm{t}}^{\mathrm{k}}$ (Eq. 2):

$$
\begin{aligned}
& \mathrm{SM}_{t}^{k}=M_{0}^{k}-\sum_{j=0}^{t} S^{k}(j) \\
& \mathrm{PSM}_{t}^{k}=\frac{\mathrm{SM}_{t}^{k}}{M_{0}^{k}} 1000
\end{aligned}
$$

where $M_{0}^{k}$ is the total number of first marriages at duration 0 (the initial amount of a given marriage cohort) in a given category $k ; S^{k}(j)$ is the number of legal separations from the specific marriage cohort in a given category $k$ and observed at time $j$; and $S M_{t}^{k}$ is the number of surviving marriages at duration $t$ and category $k=1,2, \ldots \mathrm{K}$ from the initial $M_{0}^{k}$ marriage cohort.

We calculate our survival estimates in the absence of mortality and migration. Castiglioni and Dalla-Zuanna (2008) showed that the differences of taking mortality into account or not were negligible for marriage cohorts of the 1970s. Our own calculations on 2018 data confirm that mortality rates at 15 to 49 years of age are practically the same between the married and total population, confirming that the mediating role of death on marriage dissolution by separation is negligible. A similar approach has been proposed in other low-mortality contexts (Cheng, 2016). The possible underestimation due to emigration is more complex to evaluate because of the difficulty in measuring the 
marital composition of people who emigrate. However, to reduce the risk of underestimation due to non-resident people who married in Italy and then moved abroad, we restrict the analysis to events with at least one spouse resident in Italy; also, we do not include cases of "wedding tourism." ${ }^{7}$ Overestimation is implausible given the small number of non-residents who separate in Italy. Overall, the total number of first marriages with at least one spouse resident in Italy is the great majority of all marriages each year (for example, $89.5 \%$ of total weddings celebrated in the 2000 cohort).

\section{Selected variables description}

To perform a differential analysis by selected partners' and wedding characteristics, some requirements must be met. First, the variables must be present in both the marriage and the separation data sets. Second, since both weddings/spouses and separation characteristics are measured at the time the event occurs, only those characteristics that are constant over time can be included in the analysis. Obviously, these requirements limit the range of variables that could be chosen for the study. Data on marriages include information on weddings as well as the socioeconomic and demographic characteristics of the bride and groom. Data on legal separations include similar information that allows for the comparison with data on marriages: more specifically, legal separations are collected by place of the event and include information about marriage order, ${ }^{8}$ year and place of the spouses' births, level of education ${ }^{9}$ of the spouses, rite of celebration of marriage (introduced in 1994), and property regime and citizenship (both introduced in 2000).

As for wedding features, the three variables considered are rite, property regime, and of wedding place. Wedding rite (religious or civil) is a relevant indicator of the level of modernization in union formation behaviours (De-Rose et al., 2008). The choice of the property regime (community or separation) regulates the management of property not only during the marriage but also after it is dissolved. This choice is agreed upon by the couple during or right after the wedding celebration. Since it has a long-lasting effect on spouses' wealth, it represents a resource-pooling strategy that differs according to the relative economic advantage of the spouses and can be considered a proxy of partners' relative resources (Fraboni \& Vitali, 2019). We also included the geographical macro-area of wedding celebration (north, centre, south) to account for major cultural differences in marriage propensity and in dissolution pattern (Ferro \& Salvini, 2007; Salvini \& Vignoli, 2011). The geographical area of residence is not included in the analysis, because it can vary between the spouses and between the time of marriage and that of separation. However, in $95 \%$ of cases, the macro area of the marriage celebration coincides with that of the residence of the bride, and in $94 \%$ of cases it coincides with that of the groom.

\footnotetext{
7 In 2019, there were just over 4,000 weddings between two foreign citizens who were both residing abroad. This represents $40.9 \%$ of marriages with two foreign spouses (Istat, 2021a).

8 Marital status is not included for 1995 to 1999. However, in 1993, 99.6\% of marriages were first marriages; in 2000, that figure was $98.8 \%$. We therefore consider, as an approximation, all marriages of this period as first-order marriages.

9 Until 1993, the spouses' education level included a very small proportion of missing data that were imputed. Since 2015, separations from the municipalities are affected by a higher level of incompleteness on the variable education that is no longer imputed; as a result, it is no longer being released. In future, the education level of separated individuals will be recovered through micro-level integration using the unique identifier (SIM code).
} 


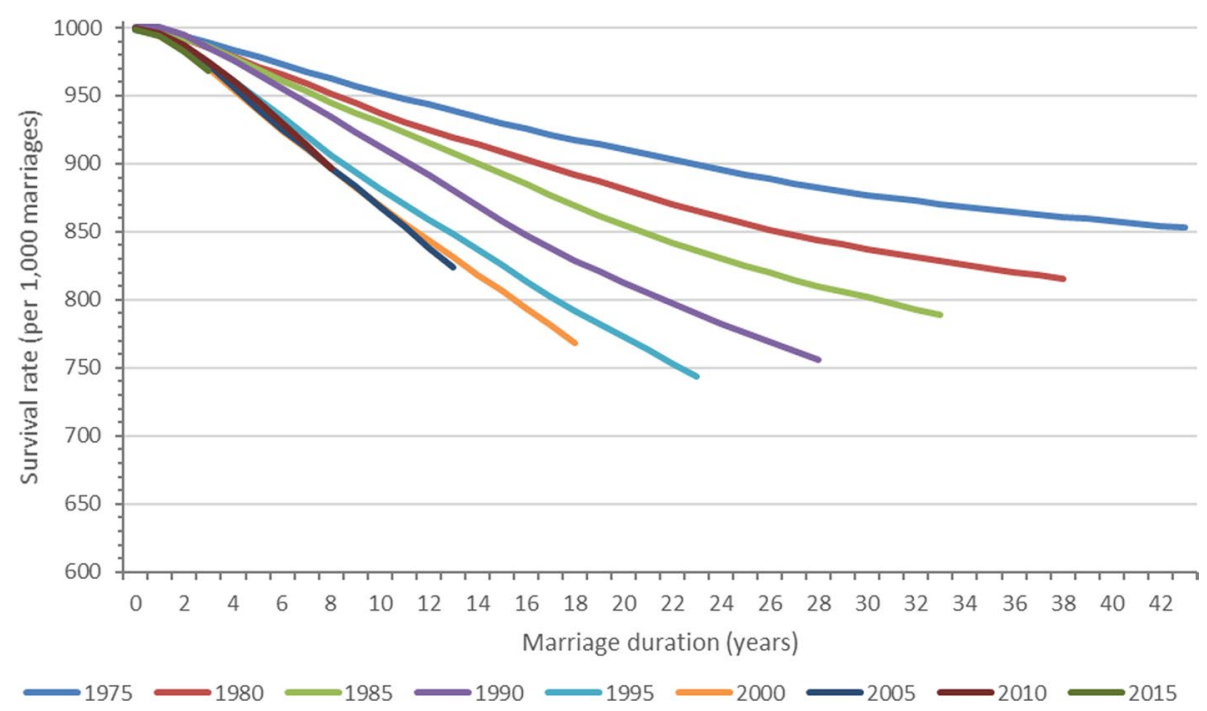

Fig. 3 First marriages surviving at separation by duration of marriage and marriage cohort (survival rates per 1000 marriages), Italy. Source Author's elaboration of Istat data on marriages and separations

For spouses' characteristics, we included age at first marriage, which is highly associated with separation risks (Lyngstat \& Jalovaara, 2010), and education level, considered both individually and with the partner's (Kalmijn, 1998). We set three levels of education: low (lower secondary education at most), medium (upper secondary education), and high (at least a university degree). Given the strong sequence rigidity in the events of transition into adulthood in Italy, and since most people have completed their education by the time of their marriage (Istat, 2014; Ongaro, 2002), education level at marriage can be considered constant over time. However, since the education level of separated people is incomplete and the variable is available only until 2014, we limit the study of separation risk by this dimension only until 2014. Finally, another variable that is becoming more relevant is citizenship. This variable has been available since 2000 in separations data, so we include it to explore differentials in survival compared to Italian spouses.

\section{Results}

The trend in the proportion of surviving marriages at separation among successive first marriage cohorts in Italy by duration of marriage is reported in Fig. 3 (Additional file 1: Table S3). We follow the marriage cohorts with different observation length over the last 30 years starting with the 1975 first marriage cohort; for every 5-year cohort, we compare survival levels at fixed durations.

Across cohorts, the proportion of surviving marriages at any duration is declining, so we observe a strong anticipatory pattern. After 2 years of marriage, virtually all marriages of the 1975 cohort are still intact (with just 6.2 separations per 1000 marriages), down to about 984 per 1000 marriages of the 2000 cohort (with a loss of almost 16 separations per 1000 marriages, more than double what we found for the initial cohort). The subsequent cohorts of the new millennium show a slightly increasing survival rate compared to the 2000 one, so that this cohort reaches a (relative) minimum. Indeed, the most recent marriage cohort included here-for 2015-has already lost 18,000 marriages 
at 2 years of marriage duration. Nevertheless, the same trend occurs at longer marriage duration, with a minimum around the year 2000 and a slowdown for the subsequent cohorts that start recovering the separation rate. Interestingly, the pace of separation rate speeds up across cohorts: if, for the 1975 cohort, after 20 years of marriage there are 911 surviving marriages, the same proportion is reached after just 7 years for the 2000 cohort. The long-term trend of increasing marital dissolution observed through legal separations and its progressive anticipation with respect to the duration of the marriage (AISP, 2011; Castiglioni \& Dalla-Zuanna, 2008; Istat, 2008) seems to stop with the onset of the new millennium.

Couples married in 2010 showed higher rates of survival at any marriage duration than previous cohorts. This could suggest that a selection process is in place, as other studies have shown that the economic hardship young adults faced in the second decade of 2000 meant higher rates of living with parents, a delay in the process of leaving home, and fewer marriages (Aassve et al., 2013; AISP, 2015). Thus, the smaller number of couples who did marry would be very motivated and highly committed to marriage.

Overall, the observed change in separation rates also derives from changes in the number of people entering the population strata who are differently exposed to the risk of marriage dissolution, all other conditions being equal (Salvini \& Vignoli, 2011). For this reason, it is necessary to keep in mind the composition variation that has occurred over time with respect to the factors considered. Over the last 30 years, marriage and spouses' characteristics changed radically (see Additional file 1: Tables S1 and S2). While the distribution by territorial division does not seem to vary much over time, the process of secularization is clearly visible considering the progressive spread of the civil rite and separation property regime. During the first two decades of the millennium, a remarkable spread of civil marriages has been observed. In 2019 in the north of Italy, these count for 2 out of 3 marriages: twice the share observed at the beginning of the period and twice the share of civil marriages in the south and the islands. A lower proportion of spouses combine their property: from half of spouses in 2000 to $27.2 \%$ in 2019 . Accordingly, the percentage of civil marriages among legal separations increased, while that with community of property decreased over the years considered. The substantial increase in women's education levels is reflected in the distribution of marriages proportion, with an increasing share of highly educated partners. Since the beginning of the millennium, the impact of the foreign population begins to be visible in first marriages data, although in $88.6 \%$ of weddings celebrated in 2015 , the bride was Italian.

These compositional changes must be kept in mind when comparing the survival curves for different categories of the same variable through time. This is worthwhile, for instance, while looking at results by age at marriage (Fig. 4). As a result of the already noted continuous process of marriage postponement ("Italian context" section above), weddings where the bride is younger than 25 have ranged from $72.0 \%$ in the 1975 marriage cohort to $11.3 \%$ in the 2015 cohort; marriages where the bride is 25 to 34 years old have gone from 24.6 to $64.5 \%$, and those where she is older than 34 have gone from 3.4 to $24.2 \%$ in these same years. In the oldest marriage cohorts, say until the 1990 cohort, the separation risk at each marriage duration is lower when the bride is younger than 25 , followed very closely by those marriages, where she is 25 to 34, while it is much higher when the woman is in the oldest age group. For example, for the 1990 cohort, after 
$<25$ years

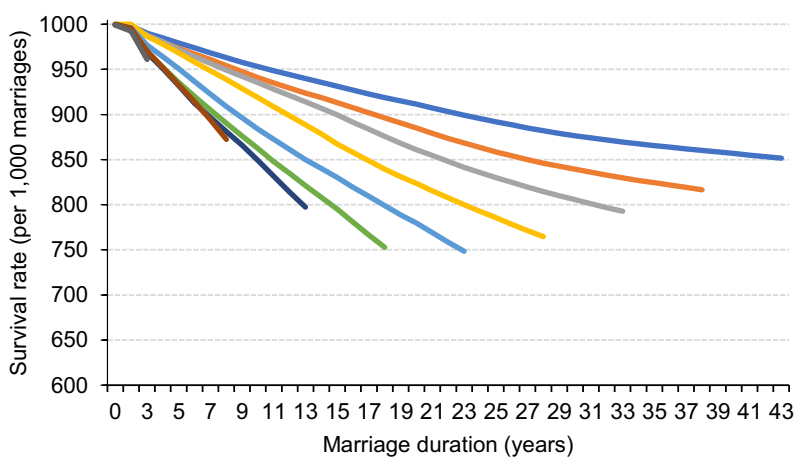

$-1975-1980-1985-1990-1995$

$-2000-2005-2010-2015$

25-34 years

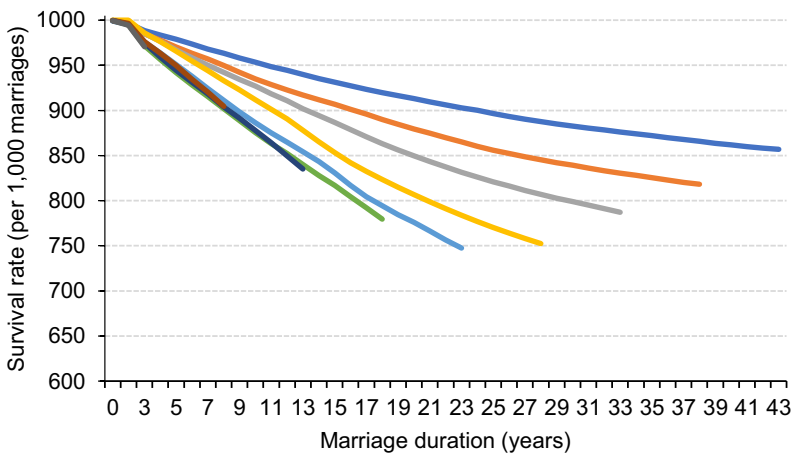

$\longrightarrow 1975-1980 \longrightarrow 1985-1990-1995$

$2000 \longrightarrow 2005 \longrightarrow 2010 \longrightarrow 2015$

$>34$ years

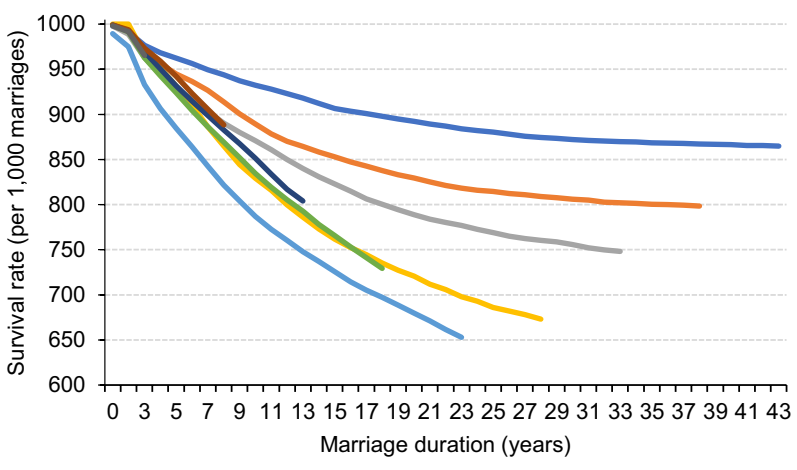

$1975-1980-1985-1990-2095$
$-2000-2005-2010-2015$

Fig. 4 First marriages surviving at separation by duration of marriage, marriage cohort, and female age at marriage (survival rates per 1000 marriages), Italy. Source Author's elaboration of Istat data on marriages and separations 
10 years of marriage, there were 919 surviving marriages, where the woman was younger than 25 at marriage (see Additional file 1: Table S4), followed by 912 surviving marriages, where she was between 25 and 34 at marriage, and only 829 surviving marriages, where she was older than 34 at marriage. Since the 1995 cohort, things begin to change: the separation risk becomes lower for marriages whose brides were between 25 and 34 at marriage (886 surviving marriages after 10 years of marriage), then shortly followed by the separation risk of those marriages, where the bride was younger than 25 (884). Still, the separation risk is higher when the bride is older than 34 at marriage (787). Since the 2005 cohort, meanwhile, the separation risk becomes higher for those marriages, where the bride was younger than 25 at marriage (849 surviving marriages after 10 years), followed by those where she is older than 34 (851), and lowest where she is in the middle age group. This last trend holds at any duration for the most recent cohorts: low female age at marriage (under 25), which is rarer and rarer, is associated with a lower stability of marriage. This is consistent with international literature (Lyngstat \& Jalovaara, 2010).

The geographical differences are also quite large (Fig. 5): while in the north of the country, separation rates are the highest at any marriage duration, and the centre of the country follows very closely, with almost the same levels at the corresponding marriage durations, in the south and islands, the dissolution of marriage is less spread out, and changes across cohorts are much slower. For instance, the 1975 cohort in the south reached 956 surviving marriages per 1000 after 20 years of marriage (Additional file 1: Table S5); in the north, the same level was reached after just 7 years in the same cohort and after just three years in the 2000 cohort. It is worthwhile to highlight that in the south, the decline in marriage survival does not reach a minimum in the 2000 marriage cohort, as happens elsewhere in the country, but the trend goes further, and the decline steadily continues to spread among the most recent cohorts.

Figure 6 illustrates the survival curves by categories of the other selected characteristics. Since, as explained above, not all the information is available and comparable for all the marriage cohorts, we show only results for the 2000, 2005, and 2010 marriage cohorts.

For each cohort, we observe that marriages celebrated with a civil ceremony are much more fragile than those celebrated with a religious ceremony. This dimension is one of the most important in terms of separation risk, as those who choose the civil rite have the highest risk of the marriage ending. It is worth noting that while religious marriages keep a constant separation risk, civil marriages that spread over the cohorts observed here have a decreasing separation risk. Thus, the gap in separation risk among couples with a civil rite and those with a religious rite is diminishing. Another clear distinction emerges between the levels of marriage separation with respect to the property regime chosen at the time of the wedding: couples who choose to combine their property appear to be consistently more resistant than those who keep their respective assets separate. Again, a selection effect at marriage might work here, since this choice of property regime is becoming rarer (Additional file 1: Table S1).

The woman's level of education is a key factor in all marriage cohorts: the most fragile marriages are those, where the woman has the highest level of education. Over time, differences by female education level seem to reduce, which is consistent with the reversal trend in the association between education and marital stability observed in other 

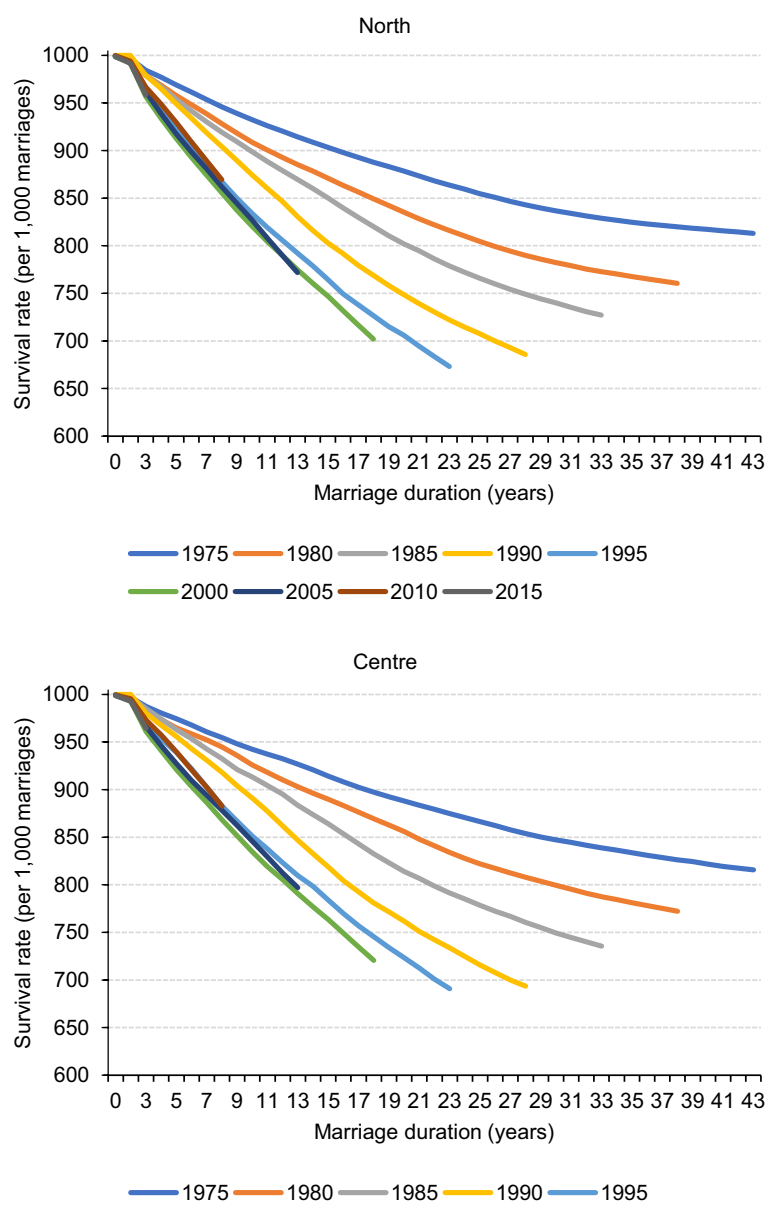

$2000-2005-2010-2015$

South

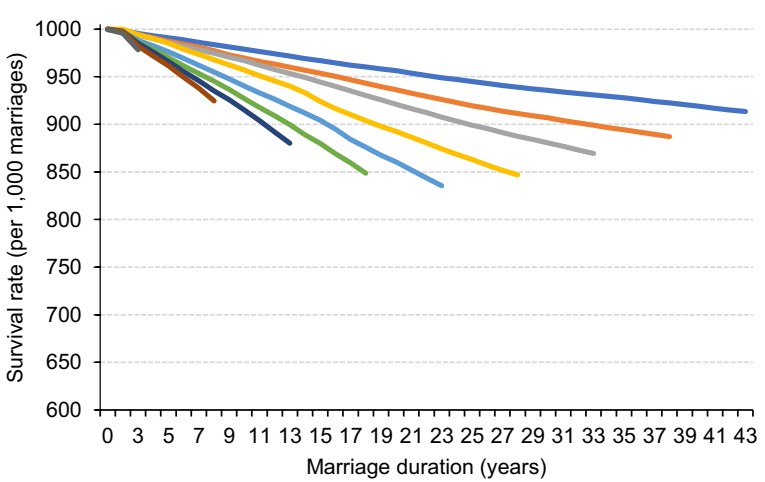

$-1975-1980-1985-1990-1995$

Fig. 5 First marriages surviving at separation by duration of marriage, marriage cohort, and geographical area (survival rates per 1000 marriages), Italy. Source Author's elaboration of Istat data on marriages and separations 
a) Rite of celebration

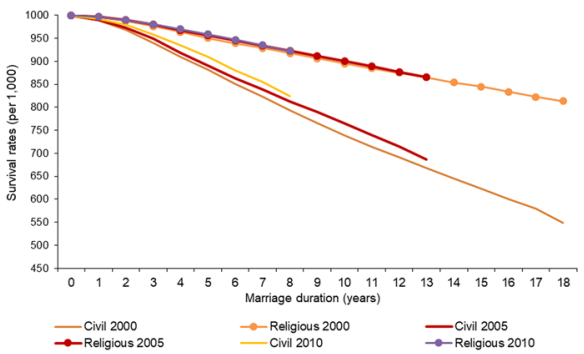

c) Female education level

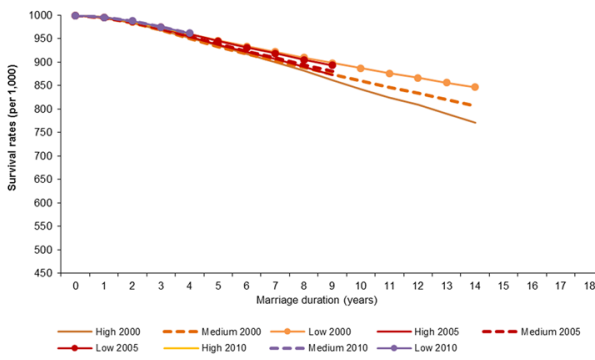

e) Couple's education level

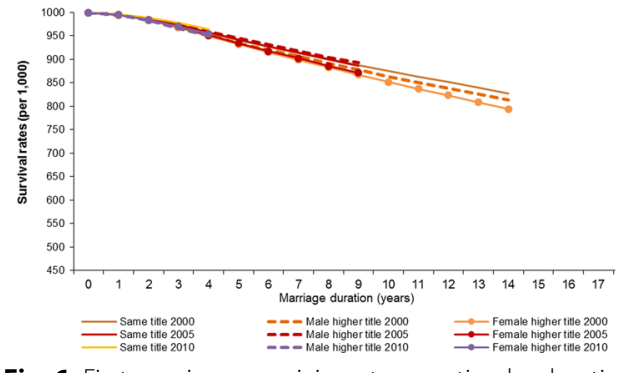

Fig. 6 First marriages surviving at separation by duration of marriage, marriage cohort, and selected

characteristics (survival rates per 1000 marriages), Italy. Source Author's elaboration of Istat data on marriages and separations b) Property regime

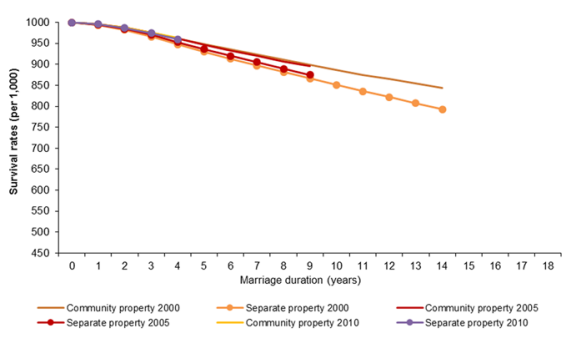

d) Female citizenship at birth

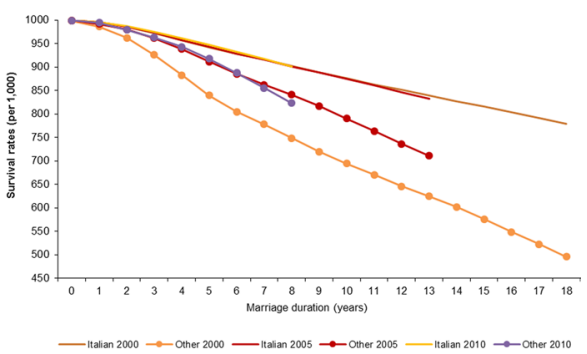

f) Couple's citizenship at birth

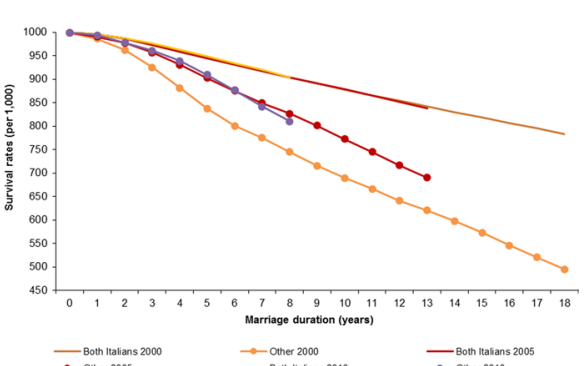

European countries (Blossfeld et al., 1995; Härkönen \& Dronkens, 2006; Kalmjin, 2013; Matysiak et al., 2014). Moreover, when considering both partners' level of education, it emerges that couples with a similar level have a lower separation risk, while, on the other hand, couples, where the woman is more educated than the man have the highest separation risk.

Another aspect that is becoming more and more relevant in Italian society since the 1990s, when immigration began to take place, is marriages between an Italian and a nonItalian and their relative separation risk. Here we include the bride's citizenship at birth and compare with that of Italian brides: a higher risk of separation associated with foreign brides emerges, although it decreases over cohorts. However, there are not a lot of first marriages with a foreign bride (from $3.8 \%$ of the 2000 first marriages to about $7 \%$ of the 2010 ones). The same trends emerge when we consider both spouses' citizenship: heterogamous marriages (between nationalities) have a higher dissolution risk than those, where both spouses are Italian, and the distance between the two couples' 
Table 1 First marriages surviving at separation by rite of celebration, property regime, geographical area, duration of marriage (in years), and marriage cohorts (survival rate per 1000 marriages), Italy

\begin{tabular}{|c|c|c|c|c|c|c|c|c|}
\hline \multirow[t]{3}{*}{ Profiles } & \multicolumn{4}{|c|}{2000} & \multicolumn{3}{|c|}{2005} & \multirow{3}{*}{$\begin{array}{l}2010 \\
\text { Duration of } \\
\text { marriage } \\
2\end{array}$} \\
\hline & \multicolumn{4}{|c|}{ Duration of marriage } & \multicolumn{3}{|c|}{$\begin{array}{l}\text { Duration of } \\
\text { marriage }\end{array}$} & \\
\hline & 2 & 5 & 7 & 10 & 2 & 5 & 7 & \\
\hline Civil rite, Community of property, North & 966 & 866 & 797 & 708 & 974 & 895 & 853 & 982 \\
\hline Civil rite, Community of property, Centre & 969 & 886 & 824 & 736 & 982 & 912 & 872 & 983 \\
\hline Civil rite, Community of property, South & 986 & 943 & 912 & 856 & 982 & 921 & 876 & 979 \\
\hline Civil rite, Separation of property, North & 960 & 842 & 769 & 670 & 965 & 858 & 797 & 972 \\
\hline Civil rite, Separation of property, Centre & 956 & 854 & 786 & 693 & 971 & 887 & 830 & 981 \\
\hline Civil rite, Separation of property, South & 982 & 928 & 889 & 822 & 982 & 920 & 870 & 985 \\
\hline Religious rite, Community of property, North & 982 & 930 & 902 & 860 & 986 & 942 & 915 & 987 \\
\hline Religious rite, Community of property, Centre & 984 & 936 & 912 & 873 & 989 & 944 & 915 & 987 \\
\hline Religious rite, Community of property, South & 995 & 975 & 962 & 941 & 993 & 971 & 956 & 992 \\
\hline Religious rite, Separation of property, North & 981 & 929 & 898 & 855 & 984 & 938 & 908 & 986 \\
\hline Religious rite, Separation of property, Centre & 983 & 933 & 903 & 858 & 985 & 936 & 910 & 987 \\
\hline Religious rite, Separation of property, South & 993 & 974 & 958 & 935 & 995 & 975 & 959 & 993 \\
\hline Total & 984 & 939 & 910 & 869 & 986 & 940 & 912 & 987 \\
\hline
\end{tabular}

Source Author's elaboration of Istat data on marriages and separations

typology is diminishing. However, heterogamous couples include a very heterogeneous group of spouses (only the bride being non-Italian, only the groom being non-Italian, or both being non-Italian), with many different sociocultural backgrounds; this needs more in-depth analyses of the respective dissolution risks.

Besides a standard univariate analysis, our data can be further exploited in a multidimensional approach to evaluate possible interactions between covariates and somewhat account for compositional aspects. Namely, in Table 1, we show surviving marriages at specific marriage duration for the three combined dimensions of rite of celebration, property regime, and geographical area.

By comparing the proportion of surviving marriages at the same marriage duration for each cohort, it is possible to single out the marriage profiles that are most and least associated with marital dissolution (see Additional file 1: Table S6 for distribution of the corresponding first marriages by the same covariate interactions). There is evidence that marriages celebrated by religious rite, choosing the combined property regime in the south of Italy, have the highest survival to separation at any duration and for all cohorts (for instance, after 2 years of marriage, 995 marriages of the 2000 cohort survive, 993 of the 2005 cohort survive, and 992 of the 2010 cohort survive). Meanwhile, the lowest proportion of surviving marriages at any marriage duration is found for marriages celebrated with the civil rite in the north, with a separation of property regime (for instance, after 2 years of marriage, 956 marriages of the 2000 cohort survive, 965 of the 2005 cohort survive, and 972 of the 2010 cohort survive). The differences between north and south are larger among those who choose separation of property than among those who choose community of property in the civil marriages group. Among those who celebrate with a religious rite, territorial differences are similar for those who choose the separation of property or the community of property regime. Comparing marriages performed 
using the civil rite, we find that the separation of property increases the risk of separation more than the community of property does, especially in the centre and in the north of the country.

\section{Discussion and future perspectives}

In this work, we illustrated the system for detecting marriages and separations in Italy based on information flows from administrative and vital statistics, with the aim of highlighting its potential in the study of union dissolution in Italy. Pooling the two exhaustive administrative sources of data of first marriages and of legal separations and calculating survival indicators, we described the marital dissolution process by marriage duration and selected characteristics of marriage cohorts in Italy from 1975 onwards. Our results clearly show the strong growth in the tendency to separate across marriage cohorts, but also a lowering tendency to separate at short marriage durations among the new millennium cohorts. This trend, although it will need to be confirmed with future evidence, is consistent with what is being observed in many European countries, where the upward trend in divorce, which lasted for more than 100 years, appears to be reversing in the early twenty-first century (Wagner, 2020).

Important differential factors also emerge: couples in the south of Italy-or more traditional ones, such as those who married with a religious rite, who chose the community of property regime, and where the bride has a low level of education-show a relatively lower tendency to separate. However, differences in survival curves among geographical areas and by rite tend to reduce with younger marriage cohorts. More interestingly, marriage stability appears to increase through the successive marriage cohorts of the new millennium for marriages celebrated with the civil rite in the north and centre of Italy for couples who choose the separate property regime and among highly educated women.

Our approach relies on the standard life table methodology that is rarely used in recent analyses of marriage dissolution, because it requires quality exhaustive data that should be properly processed when coming from independent sources, as in the case of Italy. Even in an explorative approach, this work shows how to further exploit the potential of these sources of data, not only to estimate the rates of separation mainly by marriage duration, but also to evaluate the differential survival rates by selected characteristics of the partners and of the wedding itself. While we use aggregate rather than individual data, the data can be organized in a way that allows for simple multivariate analyses of the observed differential factors. Of course, the analysis becomes complex as the number of variables and their categories increase. In addition, the combinations of each variable's category partitioning the universe under study are limited by the size of events observed. Unlike what can be studied by means of a model on individual micro-data, evaluating the determinants of marital breakdown in a causal framework is challenging.

To properly study the phenomenon of marital dissolution, individual and longitudinal data are needed to track the whole history of each marriage's partners being exposed to the risk of separation. These data would be preferable to adopt a more comprehensive multivariate approach and explicitly evaluate the role of any single factor on separation risk and to keep marriage selection effects under control. At present, only sample survey data on households allows this type of analysis in Italy; such data can also provide 
information about gender roles, opinions, and attitudes. However, the relatively low number of events observed in Italy compared to societies in which divorce is more widespread and has taken place over a longer time, the lack of an adequate couple-perspective collecting design, and the low frequency of these surveys due to their costs and respondents' burden do not make sample surveys the optimal solution.

Administrative data could be a solution in a selected number of countries with highquality registration systems-and Italy is among them-but more research is needed to connect this source to the collection of data on union histories (Boertien, 2020).

To provide a more detailed and refined analysis of legal separations in Italy based on vital statistics, the challenging step forward is to put in place an integrated marriageseparation register by linking information from different sources at the micro level. This will be built as part of a broader project of exploitation and integration of the rich information assets of the Integrated Register System (Istat, 2016b; Runci et al., 2016). In 2011, Istat adopted the Integrated System of Administrative Microdata (SIM), a database of integrated administrative microdata built to support the Istat statistical production process (Cerroni et al., 2014; Istat, 2016b; Runci et al., 2016). Supplied administrative data sets contain microdata of the statistical target units entering the system. The statistical target units of the SIM process are individuals (students, employees, tax registrants, etc.), economic units (businesses, schools and universities, hospitals, etc.), and places (addresses, geographical areas, etc.); they feed the three main subsystems (base of integration). The SIM process identifies each object (target unit) in the administrative data set and assigns it a unique and stable (over time) code (SIM code). The SIM has two purposes. First, it allows the statistical production process to use administrative data and to comply with the rules relating to the protection of personal data. Second, it guarantees the quality of data as much as possible: this is the case, for instance, for variables such as level of education or citizenship that will be checked and, when incomplete, linked from appropriate individual databases. A first attempt to exploit SIM availability was performed by integrating the most recent data on marriages with the population register. The aim was to verify the quality of information about the level of education in the marriage register. A high level of coherence between the two sources emerged when the information was present in both registers; this allowed the retrieval of incomplete information from the population register to marriages without biasing the overall distribution and preserving comparability over time. Some preliminary results on this analysis of marriages by level of education were recently disseminated (Istat, 2021b).

Once the micro-level integration is performed by means of a unique identifier (SIM code) for each spouse, it will be possible to build in marital dissolution indicators that refer to the micro-level characteristics of each partner and to the characteristics of the wedding itself. The unique identifiers will make it possible not only to use the base register of the resident population, but also to shift to other registers containing personal data of the same units, such as the register of housing units or businesses, and to complete information from there. This would result, for instance, in getting more precise and updated knowledge about the completed level of education of the partners at marriage, when it is incomplete (as we saw above) or at the exact time of their legal separation. It 
would also be possible to follow both partners and study the risk of separation according to both spouses' characteristics, thus adopting a true couple approach.

Another step forward would be to link this information on marriages and separations to the Integrated Register System (IRS). The population register represents the backbone of IRS for producing social statistics, with a row for each target unit: that is, a "usually resident person" (living in a private or institutional household). Within IRS, the core information (taken from the population register) is extended to all the social variables, including employment status and health conditions, thanks to the joint use of administrative sources and social surveys (UNECE, 2018).

The Integrated Register System, which is being completed, includes:

- basic statistical registers (individuals, businesses, and territorial entities);

- extended statistical registers (structural business statistics framework, and income register); and

- thematic statistical registers (education register).

The micro-level linkage between marriages, separations, and IRS would be relevant for couples entering the observation window of the population register-that is, from 2011 on-while it would be more demanding and time consuming if the recovery of marriage histories occurred in the previous period. For these reasons, we would like to underline the importance of the present study. In fact, this analysis is part of the preparatory activities for the wider innovation project of the data integration at the individual level described above. It aimed not only to prove the usefulness of the combined usage of these data sources but also to highlight the main dynamics of separations of marriage cohorts which deserve future deepening in the years to come.

\section{Supplementary Information}

The online version contains supplementary material available at https://doi.org/10.1186/s41118-021-00138-2.

Additional file 1: Table A1. First marriages by selected characteristics and marriage cohort, Italy (percentages and absolute values). Table S2. Demographic indicators of marriages and separations by geographical area, Italy, 2000 and 2019. Table S3. First marriages surviving at separation by duration of marriage and marriage cohort (survival rates per 1,000 marriages), Italy. Table $\mathbf{S 4}$. First marriages surviving at separation by duration of marriage, marriage cohort, and female age at marriage (survival rates per 1,000 marriages), Italy. Table S5. First marriages surviving at separation by duration of marriage, marriage cohort, and geographical area (survival rates per 1,000 marriages), Italy. Table S6. First marriages by rite of celebration, property regime, geographical area, and marriage cohort (percentages and absolute values), Italy

Acknowledgements

We acknowledge support from Istat, Thematic project n.72 "Family vulnerability", Quadro strategico, Piano di attività e Performance 2019-2021 - Istat and from Sapienza University of Rome, project “La sostenibilità economica e sociale dell'invecchiamento della popolazione", 2019.

\section{Authors' contributions}

The authors confirm that the content of the manuscript has not been published or submitted for publication elsewhere. The views and opinions expressed in this article are those of the authors and do not necessarily reflect the position of the Italian National Institute of Statistics (Istat). All authors read and approved the final manuscript.

\section{Funding}

The study has been developed under the project "La sostenibilità economica e sociale dell'invecchiamento della popolazione" PI: Alessandra De Rose funded by Sapienza University of Rome, 2019.

Availability of data and materials

The data sets used in the current study are available from Istat upon request. 


\section{Declarations}

\section{Ethics approval and consent to participate}

Any experimental research that is reported in the manuscript should have been performed with the approval of an appropriate ethics committee. Research carried out on humans must be in compliance with the Helsinki Declaration, and any experimental research on animals should follow internationally recognized guidelines.

\section{Consent for publication}

Not applicable.

Competing interests

The authors declare that they have no competing interests.

\section{Author details}

${ }^{1}$ Italian National Institute of Statistics (ISTAT), Rome, Italy. ${ }^{2}$ Sapienza University of Rome, Rome, Italy.

Received: 16 April 2021 Accepted: 10 October 2021

Published online: 30 October 2021

\section{References}

Aassve, A., Cottini, E., \& Vitali, A. (2013). Youth prospects in a time of economic recession. Demographic Research, 29(36), 949-962. https://doi.org/10.4054/DemRes.2013.29.36

Associazione Italiana per gli Studi di Popolazione AISP. (2011). Rapporto sulla popolazione. L'Italia a 150 anni dall'Unità. II Mulino.

Associazione Italiana per gli Studi di Popolazione AISP. (2015). Rapporto sulla popolazione. L'Italia nella crisi economica. II Mulino.

Associazione Italiana per gli Studi di Popolazione AISP. (2021). Rapporto sulla popolazione. L'Italia e le sfide della demografia. II Mulino.

Amato, P. R. (2000). The consequences of divorce for adults and children. Journal of Marriage and Family, 62(4), 1269-1287. https://doi.org/10.1111/j.1741-3737.2000.01269.x

Amato, P. R. (2010). Research on divorce: Continuing trends and new developments. Journal of Marriage and Family, 72(3), 650-666. https://doi.org/10.1111/j.1741-3737.2010.00723.x

Barbagli, M., \& Saraceno, C. (1998). Separarsi in Italia. II Mulino.

Blossfeld, H.-P., De-Rose, A., Hoem, J. M., \& Rohwer, G. (1995). Education, modernization, and the risk of marriage disruption: Differences in the effect of women's educational attainment in Sweden, West-Germany, and Italy. In K. O. Mason \& A.-M. Jensen (Eds.), Gender and family change in industrialized countries (pp. 200-222). Clarendon Press.

Boertien, D. (2020). The conceptual and empirical challenges of estimating trends in union stability: Have unions become more stable in Britain? In D. Mortelmans (Ed.), Divorce in Europe New insights in trends, causes and consequences of relation break-ups (pp. 17-36). Springer.

Castiglioni, M., \& Dalla-Zuanna, G. (2008). A marriage-cohort analysis of legal separations in Italy. Population, 63(1), 173-193. https://doi.org/10.1353/pop.0.0003

Castiglioni, M., \& Urbano, A. (1998). Un'analisi delle indagini correnti condotte dall'ISTAT e alcuni risultati. In A. De Rose (Ed.), Separazioni e divorzi in Italia: problemi di ricerca (pp. 9-26). SIS-GDC.

Cerroni, F., Di Bella, G., \& Galiè, L. (2014). Evaluating administrative data quality as input of the statistical production process. Rivista Di Statistica Ufficiale, 16(1-2), 117-146.

Cheng, Y.-H.A. (2016). More education, fewer divorces? Shifting education differentials of divorce in Taiwan from 1975 to 2010. Demographic Research, 34(33), 927-942. https://doi.org/10.4054/DemRes.2016.34.33

Cherlin, A., Cumberworth, E., Philip Morgan, S., \&Wimer, C. (2013). The effects of the great recession on family structure and fertility. The Annals of the American Academy of Political and Social Science, 650(1), 214-231. https://doi.org/10. $1177 / 0002716213500643$

De Leeuw, E., Hox, J., \& Luiten, A. (2018). International nonresponse trends across countries and years: An analysis of 36 years of labour force survey data. Survey Methods: Insights from the Field. https://doi.org/10.13094/SMIF-2018-00008

De-Rose, A. (1992). Socio-economic factors and family size as determinants of marital dissolution in Italy. European Sociological Review, 8(1), 71-91. https://doi.org/10.1093/oxfordjournals.esr.a036623

De-Rose, A., \& Di Cesare, M. C. (2003). Genere e scioglimento della prima unione. In A. Pinnelli, F. Racioppi, \& R. Rettaroli (Eds.), Genere edemografia (pp. 339-365). II Mulino.

De-Rose, A., Racioppi, F., \& Zanatta, A. L. (2008). Italy: Delayed adaptation of social institutions to changes in family behavior. Demographic Research, 19(19), 665-704. https://doi.org/10.4054/DemRes.2008.19.19

de Vaus, D., Gray, M., Qu, L., \& Stanton, D. (2017). The economic consequences of divorce in six OECD countries. Australian Journal of Social Issues, 52(2), 180-199. https://doi.org/10.1002/ajs4.13

Eurostat. (2020). Marriage and divorce statistics. Statistics explained. Retrieved 15 September, 2021, from https://ec.europa. eu/eurostat/statistics-explained/index.php?title=Marriage_and_divorce_statistics\#Fewer_marriages.2C_more divorces.

Ferro, I., \& Salvini, S. (2007). Separazione e divorzio in Italia. Le tendenze e le differenze regionali. Popolazione e Storia, 8(1), $125-155$.

Fraboni, R., \& Vitali, A. (2019). Gender differences in couples' matrimonial property regime in Italy. Journal of Marriage and Family, 81(4), 885-904. https://doi.org/10.1111/jomf.12574

González-Val, R., \& Marcén, M. (2017). Divorce and the business cycle: A cross-country analysis. Review of Economics of the Household, 15(3), 879-904. https://doi.org/10.1007/s11150-016-9329-x 
Grossman, W., Masselli, M., Calzaroni, M., Dias, C., Xufre, P., Di Zio M., \& Utvik, K. (2019). Guidelines on the use of estimation methods for integrating administrative sources - rev.2.1, Eurostat, ESS Vision 2020 ADMIN. Retrieved from https://ec. europa.eu/eurostat/cros/system/files/guidelines_integration_administrative_data_v2.1.pdf

Guarneri, A., Rinesi F., \& Rivellini, G. (2021, March 26). Nuovi modi di sciogliere il vincolo coniugale alla luce dei più recenti cambiamenti normativi. Neodemos. Retrieved 15 September, 2021, from https://www.neodemos.info/2021/03/26/ nuovi-modi-di-sciogliere-il-vincolo-coniugale-alla-luce-dei-piu-recenti-cambiamenti-normativi/.

Härkonen, J., \& Dronkers, J. (2006). Stability and change in the educational gradient of divorce. A comparison of seventeen countries. European Sociological Review, 22(5), 501-517.

Istat. (2008). Evoluzione e nuove tendenze dell'instabilità coniugale Argomenti n34. Istat.

Istat. (2014). Generazioni a confronto. Come cambiano i percorsi verso la vita adulta. Retrieved 15 September, 2021, from https://www.istat.it/it/files/2014/09/Generazioni-a-confronto.pdf.

Istat. (2016a, 14 November). Matrimoni, separazioni e divorzi. Anno 2015. Retrieved 15 September, 2021, from https:// www.istat.it/it/files//2016/11/matrimoni-separazioni-divorzi-2015.pdf.

Istat. (2016b). Guidelines for the quality of statistical processes that use administrative data. Version 1.1, Roma: Istat. Retrieved 15 September, 2021, from https://www.istat.it/it/files//2013/04/Linee-Guida-v1.1-Versione-inglese.pdf.

Istat. (2021a). Matrimoni, unioni civili, separazioni e divorzi, Anno 2019. Retrieved 15 September, 2021, from https://www. istat.it/it/files//2021/02/Report-matrimoni-unioni-civili-separazioni-divorzi_anno-2019.pdf.

Istat. (2021). Rapporto annuale 2021 - La situazione del Paese. Istat.

Kalmijn, M. (1998). Intermarriage and homogamy: Causes, patterns, trends. Annual Review of Sociology, 24, 395-421. https://doi.org/10.1146/annurev.soc.24.1.395

Kalmijn, M. (2007). Explaining cross-national differences in marriage, cohabitation, and divorce in Europe, 1990-2000. Population Studies, 61(3), 243-263. https://doi.org/10.1080/00324720701571806

Kalmijn, M. (2013). The educational gradient in marriage: A comparison of 25 European countries. Demography, 50(4), 1499-1520. https://doi.org/10.1007/s13524-013-0229-x

Lesthaeghe, R. (1992). The second demographic transition in Western countries: An interpretation. In M. K. Oppenheim \& A. Jensen (Eds.), Gender and family change in industrialized countries (pp. 17-62). Clarendon Press.

Lewin, A. C. (2005). The effect of economic stability on family stability among welfare recipients. Evaluation Review, 29(3), 223-240. https://doi.org/10.1177/0193841X04272558

Lyngstad, T., \& Jalovaara, M. (2010). A review of antecedents of union dissolution. Demographic Research, 23(10), 257-292. https://doi.org/10.4054/DemRes.2010.23.10

Margolis, R., Choi, Y., Hou, F., \& Haan, M. (2019). Capturing trends in Canadian divorce in an era without vital statistics. Demographic Research, 41(52), 1453-1478. https://doi.org/10.4054/demres.2019.41.52

Matysiak, A., Styrc, M., \& Vignoli, D. (2014). The educational gradient in marital disruption: A meta-analysis of European research findings. Population Studies, 68(2), 197-215. https://doi.org/10.1080/00324728.2013.856459

Mencarini, L. (2009). Le conseguenze sui partner dell'instabilità familiare. Aspetti causali e conseguenze demografiche, economiche e sociali (pp. 131-144). Bardi Editore.

Mortelmans, D. (Ed.). (2020). Divorce in Europe. New insights in trends, causes and consequences of relation break-ups. Springer.

Murphy, M. J. (1985). Demographic and socio-economic influences on recent British marital breakdown patterns. Population Studies, 39(3), 441-460.

Natali, L., \& Saraceno, C. (2017). The impact of the great recession on child poverty: The case of Italy. In B. Cantillon, Y. Chzhen, S. Handa, \& B. Nolan (Eds.), Children of austerity (pp. 170-190). UNICEF and Oxford University Press.

Ongaro, F. (2002). Low fertility in Italy between explanatory factors and social and economic implications: Consequences for the research. In Proceedings of the XLI Annual Meeting of the Italian Statistical Society, 5-7 June, Padua: CLEUP. Retrieved from https://core.ac.uk/display/53394714

Plateris, A. (1979). Divorces by marriage cohort. U.S. Department of Health, Education, and Welfare. U.S. Government Printing Office.

Preston, S. H., \& McDonald, J. (1979). The incidence of divorce within cohorts of American marriages contracted since the civil war. Demography, 16(1), 1-25. https://doi.org/10.2307/2061075

Runci, M. C., Di Bella, G., \& Galiè, L. (2016). II sistema di integrazione dei dati amministrativi in Istat. Istat Working Papers, n.18. Roma: Istat. Retrieved from https://www.istat.it/index.php/it/archivio/193056

Salvini, S., \& Vignoli, D. (2011). Things change: Women's and men's marital disruption dynamics in Italy during a time of social transformations, 1970-2003. Demographic Research, 24(5), 145-174. https://doi.org/10.4054/DemRes.2011. 24.5

Sobotka, T., \& Toulemon, L. (2008). Overview chapter 4: Changing family and partnership behaviour: Common trends and persistent diversity across Europe. Demographic Research, 19(6), 85-138. https://doi.org/10.4054/DemRes.2008.19.6

Teachman, J. D. (2002). Stability across cohorts in divorce risk factors. Demography, 39(2), 331-351. https://doi.org/10. 1353/dem.2002.0019

Timotfe, D., Stoian, A. P., Hainarosie, R., Diaconu, C., lliescu, B. D., Balan, G. G., Ciuntu, B., \& Neagoe, R. M. (2018). A review on the advantages and disadvantages of using administrative data in surgery outcome studies. Journal of Surgery, 14(3), 97-99. https://doi.org/10.7438/1584-9341-14-3-1

United Nations Economic Commission for Europe UNECE. (2007). Register-based statistics in the Nordic Countries Review of best practices with focus on population and social statistics. United Nations.

United Nations Economic Commission for Europe UNECE. (2018). Guidelines on the use of registers and administrative data for population and housing censuses. United Nations.

United Nations Economic Commission for Europe UNECE and World Bank Institute. (2010). Developing gender statistics: A practical tool. United Nations.

United Nations Statistics Division UNSD. (2019). Handbook on civil registration, vital statistics and identity management systems: Communication for development. United Nations.

Van de Kaa, D. J. (1987). Europe's second demographic transition. Population Bulletin, 42(1), 1-59. 
Vignoli, D., \& Ferro, I. (2009). Rising marital disruption in Italy and its correlates. Demographic Research, 20(4), 11-36. https://doi.org/10.4054/DemRes.2009.20.4

Vignoli, D., Matysiak, A., Styrc, M., \& Tocchioni, V. (2018). The positive impact of women's employment on divorce: Context, selection, or anticipation? Demographic Research, 38(37), 1059-1109. https://doi.org/10.4054/DemRes.2018.38.37

Wagner, M. (2020). On increasing divorce risks. In D. Mortelmans (Ed.), Divorce in Europe New insights in trends, causes and consequences of relation break-ups (pp. 37-61). Springer.

\section{Publisher's Note}

Springer Nature remains neutral with regard to jurisdictional claims in published maps and institutional affiliations.

Submit your manuscript to a SpringerOpen ${ }^{\circ}$ journal and benefit from:

- Convenient online submission

- Rigorous peer review

- Open access: articles freely available online

- High visibility within the field

Retaining the copyright to your article

Submit your next manuscript at $\boldsymbol{s p r i n g e r o p e n . c o m ~}$ 